\title{
Correlation between Myofascial Pain Dysfunction Syndrome and Cervical Pain: A Review
}

ISSN: 2637-7764

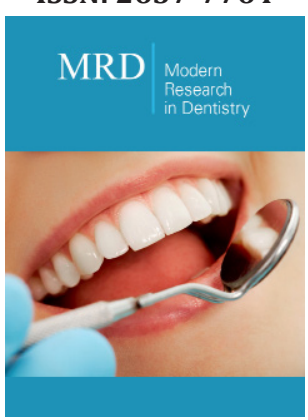

*Corresponding author: Smriti Jagdhari Golhar, Assistant Professor, Department of Oral Medicine \& Radiology, VSPM'S Dental College \& Research Center, C/O Dr.Anil Golhar, 256 Ramdaspeth, Nagpur, Maharashtra, India

Submission: 眥 December 14, 2019

Published: 僵January 28, 2020

Volume 4 - Issue 5

How to cite this article: Smriti Jagdhari Golhar. Correlation between Myofascial Pain Dysfunction Syndrome and Cervical Pain: A Review. Mod Res Dent. 4(5) MRD.000599.2020.

DOI: 10.31031/MRD.2020.04.000599

Copyright@ Smriti Jagdhari Golhar, This article is distributed under the terms of the Creative Commons Attribution 4.0 International License, which permits unrestricted use and redistribution provided that the original author and source are credited.
Smriti Jagdhari Golhar*

Department of Oral Medicine \& Radiology, VSPM'S Dental College \& Research Center, India

\section{Abstracts}

MPDS are one of the main sources of chronic orofacial pain interfering with daily activities. These disorders also are commonly associated with other symptoms affecting the head and neck region, such as headache, ear-related symptoms, cervical spine dysfunction and altered head and cervical posture.

Keywords: Myofascial Pain Dysfunction Syndrome (MPDS); Cervical pain; Craniocervical posture

Abbreviations: MPDS: Myofascial Pain Dysfunction Syndrome; TMD: Temporomandibular Disorders

\section{Introduction}

Temporomandibular disorders (TMD) consist of a group of pathologies affecting the masticatory muscles, the temporomandibular joint, and related structures. MPDS constitute a major public health problem, as they are one of the main sources of chronic orofacial pain interfering with daily activities. These disorders also are commonly associated with other symptoms affecting the head and neck region, such as headache, ear-related symptoms, cervical spine dysfunction, and altered cervical posture [1-4]. There is a documentation of interconnection between neuroanatomy and neurophysiology and its effects on orofacial area. It is noted that change in craniocervical junction can alter the occlusion patterns and jaw position. It is also noted that the masticatory system can influence the position of the craniocervical junction. Thus, myofascial dysfunction may lead to compensatory changes in the craniocervical posture and develop the neck pain.

Nicolakis et al. [5] stated in his several studies that it is postulated that posture of cervical spine and electromyographic activity of the masseter and temporalis muscles is interrelated. Shrinivas et al. [6] found 50\% MPDS patients suffering from craniocervical dysfunction in his study. According to him, MPDS in TMJ region can be caused by craniocervical dysfunction and alternatively crániocervical dysfunction can be caused by MPDS in TMJ region. Study done by Okade etal. [7] showed that cervical dysfunction may be one of the extrinsic etiologic factors for MPDS. Another study was undertaken with the objective of therapeutic evaluation of cervical dysfunction in MPDS showed cervical pain showed significant improvement to physiotherapy given for MPDS patients [2]. Therefore, it is proven that there is a positive correlation between MPDS and cervical (neck) pain. Dentist as well as orthopaedic surgeon should be aware of this association for interdisciplinary approach towards patient management.

\section{References}

1. Mortazavi H, Javadzadeh A, Delavarian Z, Mahmoodabadi RZ (2010) Myofascial Pain Dysfunction Syndrome (MPDS). Iran J Otorhinolaryngol Autumn 22(61): 131-136.

2. Golhar S, Motwani M, Golhar A (2017) Therapeutic correlation between cervical dysfunction and myofascial pain dysfunction syndrome (MPDS). The Journal of Contemporary Dental Practice 18(7): 601-606.

3. Azizi A, Sahaeebjamee M, Lawaf S, Jamalee F, Maroofi N (2007) Effects of low-level laser in the treatment of myofascial Pain dysfunction syndrome. J Dent Res Dent Clin Dent Prospects 1(2): 53-58.

4. Dragon KW, Baron S (2011) The biomechanical and functional relationship between temporomandibular dysfunction and cervical spine pain. Acta Bioeng Biomech 13(4): 93-98.

5. Nicolakis P, Erdogmus B, Kopp A, Djaber AA, Piehslinger E, et al. (2000) Exercise therapy for craniomandibular disorders. Arch Phys Med Rehabil 81(9): 1137-1142. 
6. Shrinivas K, Sumanth KS, Shrinivassan V, Kaveri BN, Chopra SS (2002) Craniocervical dysfunction levels in MPDS patient. JIOMAR (3\&4): 98102.
7. Okade D, Naikmasur VG, Guttal KS, Nagaraj T, Sinha P (2014) Evaluation of cervical dysfunction in patients with myofascial pain dysfunction syndrome: a prospective study. Int J Contemp Dent 5: 5-10.

\section{For possible submissions Click below:}

